\title{
MENENTUKAN PEMENANG KONVENSI QUALITY IMPROVEMENT CIRCLE DENGAN METODE WEIGHTED PRODUCT DAN SIMPLE ADDITIVE WEIGHTING
}

\author{
Deni Kurniawan', Arif Budimansyah Purba², Dedih ${ }^{3}$ \\ 1sidenikurniawan@gmail.com, 2arifbudimansyahpurba@gmail.com \\ 3dedih@stmik-kharisma.ac.id \\ Sistem Informasi, STMIK Kharisma Karawang
}

\begin{abstract}
Abstrak
Pengambilan keputusan untuk menentukan pemenang dalam suatu konvensi atau kompetisi merupakan suatu hal yang cukup sulit dilakukan secara konvensional. Kesulitan akan semakin terasa dengan bertambahnya alternatif dan kriteria yang dimasukkan. Sistem Pendukung Keputusan (SPK) merupakan salah satu solusi dalam mengatasi kesulitan tersebut. SPK adalah sekumpulan prosedur berbasis model untuk data pemrosesan dan penilaian guna membantu para manager mengambil keputusan. SPK akan melakukan perhitungan dan menampilkan hasil berupa rekomendasi siapa pemenang dalam konvensi tersebut. Ada 2 metode yang diusulkan dalam penelitian kali ini yaitu Simple Additive Weighting (SAW) dan Weighted Product (WP). Dari metode-metode tersebut akan dilakukan perbandingan metode mana yang lebih baik untuk diterapkan dalam SPK menentukan pemenang konvensi Quality Improvement Circle (QIC) yang dilaksanakan di sebuah perusahaan. Dalam pengembngan SPK digunakan metode pengembangan sistem atau System Development Life Cycle (SDLC)Waterfall. Metode SAP dan WP dapat digunakan dalam SPK konvensi QIC dan hasil SAW bernilai tetap sedangkan metode WP memiliki nilai akhir yang berubah sesuai banyaknya alternatif.
\end{abstract}

Kata kunci : SPK, QIC, SAW, WP, Waterfall

\section{Pendahuluan}

Perkembangan teknologi khususnya teknologi berbasis komputer sangat cepat dan terus berkembang dari waktu ke waktu. Sistem-sistem yang asalnya dilakukan oleh manusia kini banyak diganti dengan sistem yang sudah terkomputerisasi. Dalam sebuah perusahaan peranan teknologi berbasis komputer sangat dibutuhkan, salah satunya adalah bagaimana membuat sebuah keputusan yang tepat berdasarkan data-data yang sudah ada. Sistem Pendukung Keputusan atau Decission Suport System (DSS) yang merupakan sistem berbasis komputer yang interaktif, yang membantu pengambil keputusan memanfaatkan data dan model untuk menyelesaikan masalah-masalah yang tak terstruktur. DSS sebagai sekumpulan prosedur berbasis model untuk data pemrosesan dan penilaian guna membantu para manager mengambil keputusan. Sistem ini membantu para pengambil keputusan agar lebih cepat dan tepat dalam membuat sebuah keputusan [1].

Quality Improvement Circle (QIC) adalah sebuah kelompok kegiatan dimana sejumlah karyawan terdiri dari 3-7 orang dengan pekerjaan yang sejenis yang bertemu secara berkala untuk membahas dan memecahkan masalah-masalah pekerjaan dan lingkungannya dengan tujuan meningkatkan mutu usaha dengan menggunakan perangkat kendali mutu dengan delapan tahapan dan menggunakan tujuh alat atau tool. Kelompok ini disebut dengan circle. Tujuan dari kegiatan ini adalah mencari solusi atas tiap-tiap permasalahan yang sering muncul dilapangan. Untuk itu penggunaan DSS diharapkan mampu membantu Komite QIC dalam menentukan pemenang dengan hasil yang lebih obyektif dibandingkan dengan perhitungan secara manual yang terkadang dipengaruhi nilai-nilai subyektif dari juri artau komite QIC. Metode DSS yang digunakan dalam penelitian kali ini adalah metode Weighted Product Method (WP Method) dan Simple Additive Weighting (SAW). Weigthted Product adalah metode penyelesaian dengan menggunakan perkalian untuk menghubungkan rating atribut, dimana rating harus dipangkatkan terlebih dahulu dengan bobot atribut yang bersangkutan. Sedangkan Simple Additive Weighting (SAW) adalah mencari penjumlahan terbobot dari rating kinerja pada setiap alternatif pada semua atribut [2].

Dalam merancang DSS ini digunakan metode pengembangan sistem adalah metode Waterfall dengan System Development Life Cycle (SDLC) dari Satzinger. SDLC adalah suatu metodologi pengembangan perangkat lunak yang mengusulkan pendekatan kepada perangkat lunak sistematik dan sekuensial yang mulai pada Project planning phase, Analysis phase, Design phase, Implementation phase dan Support phase [3]. 


\section{Metode}

\subsection{Bahan Penelitian}

Beberapa rujukan dipergunakan seperti buku-buku, jurnal, dan beberapa sumber lain yang dapat dipercaya untuk menunjang penelitian ini. Bertanya langsung ke narasumber dan observasi lapangan dilakukan untuk mendapatkan data-data yang akurat

\subsection{Alat Penelitian}

Suatu penelitian memerlukan alat pendukung dalam melaksanakan penelitiannya agar penelitian dapat berjalan dengan baik. Alat penelitian yang digunakan dalam penelitian ini meliputi perangkat keras (hardware) dan perangkat lunak (software).

\subsection{Metode Pengembangan Sistem}

Metode pengembangan yang digunakan adalah metode SDLC Waterfall yaitu suatu metodologi pengembangan perangkat lunak yang mengsulkan pendekatan kepada perangkat lunak sistematis dan sekuensial yang dimulai pada tahap Project planning phase, Analysis phase, Design phase, Implementation phase, dan Support phase [2].

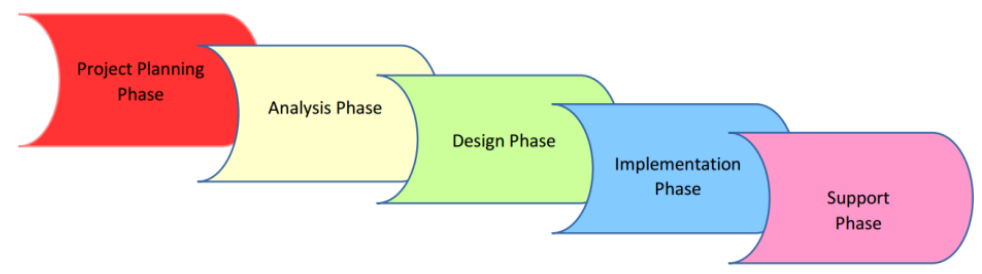

Gambar 1. The Waterfall Approach to The SDLC

\subsubsection{Project Planning Phase}

Pada tahapan ini dilakukan penelitian terlebih dahulu untuk menyaring data serta informasi yang terkait, yaitu melakukan teknik dengan cara mengidentifikasi masalah, pengumpulan data, menganalisis teori, pembuatan Metode Simpale Additive Weighting lebih disarankan dalam SPK konvensi QIC.

Tabel 1. Tabel Deskripsi Project Planing Phase

\begin{tabular}{|c|c|c|}
\hline No. & Tahapan & Deskripsi \\
\hline 1. & Identifikasi Masalah & $\begin{array}{l}\text { 1) Bagaimana cara mementukan pemenang dalam kompetisi QIC } \\
\text { dengan metode Weighted Product (WP)?. } \\
\text { 2) Bagaimana cara mementukan pemenang dalam kompetisi QIC } \\
\text { dengan metode Simple Additive Weighting (SAW)?. } \\
\text { 3) Metode mana yang lebih baik dalam perhitungannya?. } \\
\text { 4) Bagaimana implementasi metode tersebut ke dalam sebuah } \\
\text { program berbasis web dengan metode pengembangan atau } \\
\text { System Development Life Cycle (SDLC) dan pendekatan Object } \\
\text { Oriented Aproach (OOA)?. }\end{array}$ \\
\hline 2. & Pengumpulan Data & $\begin{array}{l}\text { Mengumpulkan data yang diperlukan dengan cara: } \\
\text { a) Wawancara secara langsung ke narasumber yaitu komite QIC } \\
\text { PT Adyawinsa Stamping Industries. } \\
\text { b) Studi pustaka mengenai QIC, tahapan pelaksanaan, kriteria- } \\
\text { kriteria dan lain-lain. Buku-buku dan jurnal digunakan untuk } \\
\text { lamdasan teoritis dan mencari kemungkinan solusi berdasarkan } \\
\text { teori tersebut. } \\
\text { c) Observasi lapangan dengan melihat proses QIC. }\end{array}$ \\
\hline 3. & Pembuatan Jadwal & $\begin{array}{l}\text { Membuat rencana kerja tentang penelitian ini dengan menghitung } \\
\text { waktu yang diperlukan dari awal proyek sampai tahap implementasi } \\
\text { dan pengujian dilapangan pada saat konvensi QIC berlangsung. }\end{array}$ \\
\hline 4. & Mencari Solusi & $\begin{array}{l}\text { Dari data-data yang dikumpulkan, dibuat sebuah rumusan } \\
\text { permasalahan yang dihadapi oleh komite QIC. Kemudian dibuat } \\
\text { sebuah solusi yang bisa mengatasi permasalahan tersebut } \\
\text { berdasarkan hasil analisis teori-teori yang ada. }\end{array}$ \\
\hline
\end{tabular}


5. Mendefinisikan Kebutuhan
Kebutuhan yang digunakan dalam penelitian tidak terlalu banyak. Cukup dengan satu unit komputer dengan aplikasi atau program yang mendukung beserta satu unit alat cetak berupa printer.

\subsubsection{Analysis Phase}

\section{A. Analisis Teori}

Diagram alir (Flow Chart) metode SAW dan WP yang menggambarkan tahapan Sistem Pendukung Keputusan Konvensi QIC.

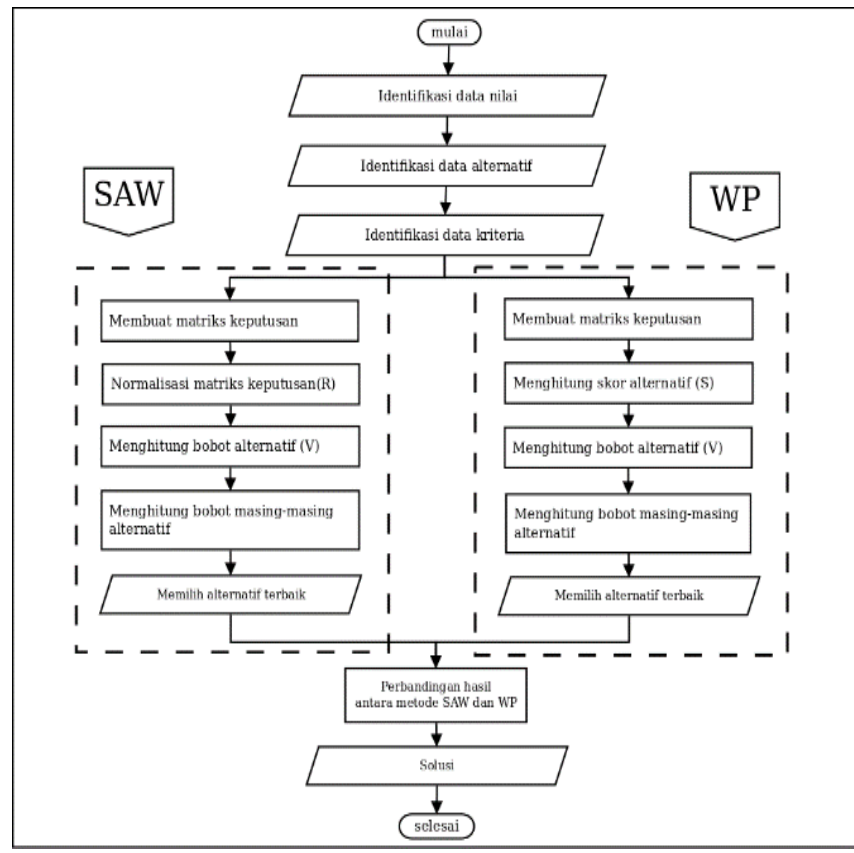

Gambar 2. Flowchat Metode SAW dan WP

\section{B. Analisis Sistem}

Analisis sistem dilakukan pada tahap ini dengan menggunakan Object Oriented Analysis, yaitu :
a) System Activies
a. Deskripsi Use Case dan Aktor
b. Skenario Use Case
c. Use Case Diagram
b) Class Diagram
c) Object Interaction (Sequence Diagram)
d) Object Behavior (Activity Diagram)

\subsubsection{Design Phase}

Pada tahap desain ini merupakan tahap pembuatan atau perancangan sistem yang akan dibuat, seperti desain basis data dengan rincian rancangan tabel basis data, normalisasi tabel basis data, relasi antar table basisdata, desain proses dan dseain antar muka sistem tersebut.Pendesainan yang digunakan yaitu desain berbasis Object Oriented Design (OOD).

\subsubsection{Implementasi Phase}

Tahapan implementasi sistem merupakan tahap dimana sistem siap untuk diopersikan. Tahap ini merupakan lanjutan dari tahap analisis dan desain sistem.Pada tahap ini sistem akan diuci coba kepada pengguna apakah sistem yang dibuat sudah sesuai dengan tujuannya,sehingga pengguna dapat memberikan masukan jika masih ada kekurangan pada sistem ini untuk pengembangan selnajutnya.Teknik yang digunakan pada pemrograman menggunakan Object Oriented Programming (OOP). Dengan menggunakan metode Object oriented Programming (OOP) memudahkan untuk memodifikasi source code yang sudah dibuat. Pada tahapan ini dilakukan beberapa tahapan, yaitu :

1. Pemasangan Sistem

Pada tahapan ini menjelaskan beberapa proses pemasangan sistem pada komputer atau laptop. 
2. Pengujian Sistem

Pengujian terhadap sistem terdapat 2 tahap pengujian yaitu blackbox dan whitebox. Pengujian blackbox hanya mengamati hasil eksekusi dan hanya mengevaluasi interfacenya dan fungsionalitasnya. Pengujian whitebox untuk menguji semua statemen pada program.

\subsubsection{Support Phase}

Tahap yang tidak kalah penting dalam sebuah pengembangan sistem adalah support phase atau tahap dukungan terhadap sistem yang sudah diterapkan di komite QIC. Dukungan yang diberikan berupa perbaikan bugs atau error di kemudian hari bila ditemukan dan upgrade sistem bila diperlukan.

\section{Hasil dan Pembahasan}

\subsection{Project Planning Phase}

Tahap pertama yang dilakukan adalah tahap perencanaan atau project planning phase untuk menjelaskan kegiatan-kegiatan yang akan dilakukan.

Tabel 2. Project Planing Phase

\begin{tabular}{|c|c|c|}
\hline No. & Tahapan & Deskripsi \\
\hline 1. & Identifikasi Masalah & Sistem Pendukung Keputusan konvensi Quality Improvement Circle. \\
\hline 2. & Pengumpulan Data & $\begin{array}{l}\text { Mengumpulkan data seperti alur kegiatan QIC, kriteria-kriteria, data } \\
\text { circle, tata cara penilaian dan data pendukung lainnya. }\end{array}$ \\
\hline 3. & & etode WP dan SDLC Waterfall. \\
\hline 4. & Pembuatan Jadwal & Ilan Maret sampai bulan Mei \\
\hline 5. & Mencari Solusi & $\begin{array}{l}\text { Mengetahui perolehan rangking tiap-tiap circle dan pemenang dari } \\
\text { konvensi QIC. }\end{array}$ \\
\hline 6. & $\begin{array}{l}\text { Mendefinisikan } \\
\text { Kebutuhan }\end{array}$ & $\begin{array}{l}\text { Satu unit laptop dan sebuah printer serta aplikasi-aplikasi seperti } \\
\text { WPS writer, WPS spreadsheet, Geany editor, mySql, Apache, } \\
\text { Firefox Web Browser. }\end{array}$ \\
\hline
\end{tabular}

\subsection{Analysis Phase}

\subsubsection{Analisis Teori}

Indeks Nilai

Dari hasil penelitian yang dilakukan di PT Adyawinsa Stamping Industries didapat data-data sebagai berikut :

Tabel 3. Indeks Penilaian

\begin{tabular}{cccc}
\hline No. & Indeks & Keterangan & Nilai \\
\hline 1. & $\mathrm{~K}$ & Kurang & 1 \\
2. & $\mathrm{C}$ & Cukup & 2 \\
3. & $\mathrm{~B}$ & Baik & 3 \\
4. & SB & Sangat Baik & 4
\end{tabular}

Tabel 4. Alternatif

\begin{tabular}{ccll}
\hline No. & Indeks Circle & Nama Circle & Departemen \\
\hline 1. & A1 & Makino & Engeenering \\
2. & A2 & Cartenz & Welding \\
3. & A3 & Dipping & Stamping \\
4. & A4 & Wendis & Welding \\
5. & A5 & Kompi & Maintenance \\
6. & A6 & Tempa & Stamping \\
7. & A7 & Kasep & Pinting \\
8. & A8 & Coin & Quality \\
9. & A9 & Batik & Puchasing \\
10. & A10 & Sate & PPIC \\
\hline
\end{tabular}


Tabel 5. Kriteria

\begin{tabular}{|c|c|c|c|c|}
\hline No. & $\begin{array}{l}\text { Indeks } \\
\text { Kriteria }\end{array}$ & Kriteria Penilaian & Bobot & Aspek Penilaian \\
\hline 1. & C1 & $\begin{array}{l}\text { - Pemilihan tema. } \\
\text { - Kondisi saat ini. }\end{array}$ & $12 \%$ & $\begin{array}{l}\text { - Kolerasi tema berdasar KPI. } \\
\text { - Perbandingan kondisi standar } \\
\text { dengan kondisi sebenarnya (actual } \\
\text { condition). }\end{array}$ \\
\hline 2. & $\mathrm{C} 2$ & Target & $4 \%$ & $\begin{array}{l}\text { Target terukur dengan angka dengan } \\
\text { waktu penyelesaian yang jelas. }\end{array}$ \\
\hline 3. & C3 & $\begin{array}{l}\text { - Ketajaman masalah. } \\
\text { - Analisis masalah pengujian. } \\
\text { - Scientific Approach. }\end{array}$ & $40 \%$ & $\begin{array}{l}\text { - Ketajaman analisis dalam mencari } \\
\text { penyebab. } \\
\text { - Identifikasi penyebab dominan dan } \\
\text { pengujian faktor penyebab. } \\
\text { - Adanya literature terkait dan } \\
\text { benchmark. }\end{array}$ \\
\hline 4. & C4 & $\begin{array}{l}\text { - Perencanaan perbaikan. } \\
\text { - Peranan pihak terkait. }\end{array}$ & $8 \%$ & $\begin{array}{l}\text { - Perbaikan menggunakan } 5 \mathrm{~W} 1 \mathrm{H} \text {. } \\
\text { - Adanya keterlibatan pihak lain. }\end{array}$ \\
\hline 5. & C5 & $\begin{array}{l}\text { - Upaya perbaikan. } \\
\text { - Monitoring perbaikan. }\end{array}$ & $4 \%$ & $\begin{array}{l}\text { - Tingkat kesulitan perbaikan. } \\
\text { - Bukti perbaikan dan ada perubahan } \\
\text { data selama perbaikan. }\end{array}$ \\
\hline 6. & C6 & $\begin{array}{l}\text { - Evaluasi hasil. } \\
\text { - Peningkatan kompetensi. }\end{array}$ & $5 \%$ & $\begin{array}{l}\text { - Pencapaian hasil terhadap target } \\
\text { dilengkapi data yang komprehensip. } \\
\text { - Peningkatan skill, knowledge dan } \\
\text { attitude seluruh anggota. }\end{array}$ \\
\hline 7. & $\mathrm{C7}$ & - Tema berikutnya. & $15 \%$ & $\begin{array}{l}\text { - Adanya standarisasi baru agar hasil } \\
\text { perbaikan tetap konsisten (SOP, } \\
\text { pokayoke, sosialiasi, monitoring dan } \\
\text { maintenance). } \\
\text { Jaminan kapabilitas proses. } \\
\text { - Tema baru yang berkelanjutan untuk } \\
\text { menjaga konsistensi perbaikan }\end{array}$ \\
\hline 8. & $\mathrm{C} 8$ & $\begin{array}{l}\text { - Sistematika penulisan. } \\
\text { - Kesesuaian terhadap aturan. } \\
\text { - Keterlibatan atasan. }\end{array}$ & $5 \%$ & $\begin{array}{l}\text { - Singkat, jelas, berurut sesuai kaidah } \\
8 \text { langkah. } \\
\text { - Ketepatan waktu pengumpulan dan } \\
\text { format risalah sesuai aturan. } \\
\text { - Adanya keterlibatan atasan dalam } \\
\text { penyusunan risalah. }\end{array}$ \\
\hline 9. & C9 & $\begin{array}{l}\text { - Kerjasama tim } \\
\text { - Ketepatan waktu presntasi }\end{array}$ & $7 \%$ & $\begin{array}{l}\text { - Alur presentasi: cara penyampaian } \\
\text { mudah dipahami dan inti perbaikan } \\
\text { tersampaikan. } \\
\text { - Kreativitas penyampaian: } \\
\text { menggunakan animasi, peraga atau } \\
\text { alat bantu yang tepat. } \\
\text { - Penggunaan bahasa, mudah } \\
\text { dimengerti dan jelas. } \\
\text { - Intonasi dan gesture, suara jelas, } \\
\text { tidak monoton dan menggunakan } \\
\text { body language. } \\
\text { - Koordinasi dan komunikasi antara } \\
\text { presentator dan anggota lainnya. } \\
\text { - Semua anggota menguasai materi } \\
\text { dengan baik. } \\
\text { - Penggunaan waktu yang optimal } \\
\text { sesuai aturan. }\end{array}$ \\
\hline
\end{tabular}

Sebelum melakukan perhitungan, maka dilakukan perbaikan bobot terlebih dahulu sehingga $\mathrm{W}=1$. Seperti terlihat dalam tabel berikut. 
Tabel 6. Perbaikan Bobot

\begin{tabular}{ccc}
\hline $\begin{array}{c}\text { Indeks } \\
\text { Penilaian }\end{array}$ & \multicolumn{2}{c}{ Perbaikan Bobot } \\
Sebelum & Sesudah \\
\hline C1 & $12 \%$ & 0,12 \\
C2 & $4 \%$ & 0,04 \\
C3 & $40 \%$ & 0,4 \\
C4 & $8 \%$ & 0,08 \\
C5 & $4 \%$ & 0,04 \\
\hline
\end{tabular}

\begin{tabular}{ccc}
\hline Indeks & \multicolumn{2}{c}{ Perbaikan Bobot } \\
\cline { 2 - 3 } Penilaian & Sebelum & Sesudah \\
\hline C6 & $5 \%$ & 0,05 \\
C7 & $15 \%$ & 0,15 \\
C8 & $5 \%$ & 0,05 \\
C9 & $7 \%$ & 0,07 \\
\hline
\end{tabular}

\section{A. Metode Simple Additive Weighting (SAW)}

1. Membuat Matriks Keputusan

Tabel 7. Matriks Keputusan

\begin{tabular}{c|ccccccccc}
\hline & C1 & C2 & C3 & C4 & C5 & C6 & C7 & C8 & C9 \\
\hline A1 & 3 & 2 & 2 & 2 & 2 & 4 & 3 & 2 & 2 \\
A2 & 3 & 3 & 3 & 2 & 3 & 3 & 2 & 3 & 2 \\
A3 & 2 & 3 & 4 & 2 & 2 & 2 & 2 & 3 & 3 \\
A4 & 2 & 4 & 2 & 3 & 4 & 4 & 2 & 4 & 3 \\
A5 & 4 & 2 & 3 & 3 & 2 & 2 & 3 & 2 & 2 \\
A6 & 3 & 3 & 2 & 2 & 3 & 2 & 3 & 3 & 3 \\
A7 & 4 & 4 & 4 & 2 & 2 & 2 & 2 & 3 & 3 \\
A8 & 2 & 2 & 2 & 2 & 4 & 3 & 3 & 2 & 2 \\
A9 & 2 & 2 & 3 & 2 & 2 & 2 & 2 & 4 & 3 \\
A10 & 3 & 3 & 2 & 2 & 2 & 4 & 2 & 2 & 3 \\
\hline
\end{tabular}

\section{Normalisasi Matriks}

Normalisasi dilakukan dengan rumus berikut ini :

$$
\begin{aligned}
& r_{i j}=\frac{x_{i j}}{\max x_{i j}}, \text { jika } \mathrm{j} \text { atribut keuntungan (benefit). } \\
& r_{i j}=\frac{\min x_{i j}}{x_{i j}}, \text { jika j atribut biaya (cost). }
\end{aligned}
$$

Melihat pada tabel 7 , semua kriteria bertipe keuntungan (benefit) maka pada tahap berikutnya dalam membuat table normalisasi nilai masing-masing kriteria dibagi dengan nilai maksimum dari 0.50

Tabel 8. Hasil Normalisasi Matriks

\begin{tabular}{c|ccccccccc}
\hline & C1 & C2 & C3 & C4 & C5 & C6 & C7 & C8 & C9 \\
\hline A1 & 0.75 & 0.50 & 0.50 & 0.67 & 0.50 & 1.00 & 1.00 & 0.50 & 0.67 \\
A2 & 0.75 & 0.75 & 0.75 & 0.67 & 0.75 & 0.75 & 0.67 & 0.75 & 0.67 \\
A3 & 0.50 & 0.75 & 1.00 & 0.67 & 0.50 & 0.50 & 0.67 & 0.75 & 1.00 \\
A4 & 0.50 & 1.00 & 0.50 & 1.00 & 1.00 & 1.00 & 0.67 & 1.00 & 1.00 \\
A5 & 1.00 & 0.50 & 0.75 & 1.00 & 0.50 & 0.50 & 1.00 & 0.50 & 0.50 \\
A6 & 0.75 & 0.75 & 0.50 & 0.67 & 0.75 & 0.50 & 1.00 & 0.75 & 1.00 \\
A7 & 1.00 & 1.00 & 1.00 & 0.67 & 0.50 & 0.50 & 0.67 & 0.75 & 1.00 \\
A8 & 0.50 & 0.50 & 0.50 & 0.67 & 1.00 & 0.75 & 1.00 & 0.50 & 0.67 \\
A9 & 0.50 & 0.50 & 0.75 & 0.67 & 0.50 & 0.50 & 0.67 & 1.00 & 1.00 \\
A10 & 0.75 & 0.75 & 0.50 & 0.67 & 0.50 & 1.00 & 0.67 & 0.50 & 1.00 \\
\hline
\end{tabular}

\section{Menghitung Bobot}

Pada tahap ini dilakukan perangkingan yaitu dengan menjumlahkan matriks normalisasi dengan setiap kriteria yang telah ditentukan. Yaitu kriteria penilaian dan presentase bobot nilai, lalu hasil dari matriks normalisasi di kalikan dengan bobot presentase. Sebagai contoh, penulis mengambil data Makino dengan rumus sebagia berikut : 


$$
v_{i}=\sum_{j=1}^{n} w_{j} r_{i j}
$$

$$
\begin{aligned}
V_{i}= & \text { nilai prefensi. } \\
w_{j}= & \text { bobot rangking, dimana jumlah } \\
& \text { bobot rangking sama dengan } 1 . \\
r_{i j}= & \text { rating kinerja ternormalisasi. }
\end{aligned}
$$

$$
\begin{aligned}
V_{i}= & \left(0.75^{*} 0,12\right)+\left(0.50^{*} 0,04\right)+\left(0.50^{*} 0,4\right) \\
& +\left(0.67^{*} 0,08\right)+\left(0.50^{*} 0,04\right)+\left(1.00^{*} 0,05\right) \\
& +\left(1.00^{*} 0,15\right)+\left(0.50^{*} 0,05\right)+\left(0.67^{*} 0,07\right) \\
V_{i}= & 0.66
\end{aligned}
$$

\section{Menghitung Skor Masing-masing Alternatif}

Perhitungan yang sama diterapkan untuk circle yang lainnya, sehingga didapat nilai prefensi dari masing-masing circle. Tabel dibawah merupakan hasil perhitungan masing-masing circle.

Tabel 9. Nilai $\boldsymbol{V}$ Masing Alternatif

\begin{tabular}{cc}
\hline Nama Circle & V \\
\hline Makino & 0,66 \\
Cartenz & 0,73 \\
Dipping & 0,80 \\
Wendis & 0,69 \\
Kompi & 0,79 \\
\hline
\end{tabular}

\begin{tabular}{cc}
\hline Nama Circle & V \\
\hline Tempa & 0,69 \\
Kasep & 0,87 \\
Coin & 0,63 \\
Batik & 0,70 \\
Sate & 0,64 \\
\hline
\end{tabular}

\section{Memilih Alternatif Terbaik}

Jika diurutkan dari nilai tertinggi sampai nilai terendah maka circle Kasep memiliki nilai skor tertinggi. Dengan demikian circle Kasep merupakan pemenang dari konvensi QIC berdasarkan perhitungan menggunakan metode SAW. Hasil perhitungan ini bukan keputusan akhir dalam penilaian QIC, akan tetapi merupakan sebuah pendukung keputusan bagi para manajer dalam menentukan pemenang konvensi QIC.

Tabel 10. Perangkingan Alternatif Metode SAW

\begin{tabular}{ccc}
\hline Rangking & Nama Circle & V \\
\hline 1 & Kasep & 0,87 \\
2 & Dipping & 0,80 \\
3 & Kompi & 0,79 \\
4 & Cartenz & 0,73 \\
5 & Batik & 0,70 \\
\hline
\end{tabular}

\begin{tabular}{ccc}
\hline Rangking & Nama Circle & V \\
\hline 6 & Wendis & 0,69 \\
7 & Tempa & 0,69 \\
8 & Makino & 0,66 \\
9 & Sate & 0,64 \\
10 & Coin & 0,63 \\
\hline
\end{tabular}

\section{B. Metode Weighted Product (WP)}

Langkah-langkah yang digunakan dalam metode WP hampir sam dengan metode SAW. Perbedaannya hanya terletak pada cara menghitungnya saja.

\section{Membuat Matriks Keputusan}

Tabel 11. Matriks Keputusan

\begin{tabular}{c|lllllllll}
\hline & $\mathbf{1}$ & $\mathbf{2}$ & $\mathbf{3}$ & $\mathbf{4}$ & $\mathbf{5}$ & $\mathbf{6}$ & $\mathbf{7}$ & $\mathbf{8}$ & $\mathbf{9}$ \\
\hline A1 & 3 & 2 & 2 & 2 & 2 & 4 & 3 & 2 & 2 \\
A2 & 3 & 3 & 3 & 2 & 3 & 3 & 2 & 3 & 2 \\
A3 & 2 & 3 & 4 & 2 & 2 & 2 & 2 & 3 & 3 \\
A4 & 2 & 4 & 2 & 3 & 4 & 4 & 2 & 4 & 3 \\
A5 & 4 & 2 & 3 & 3 & 2 & 2 & 3 & 2 & 2 \\
A6 & 3 & 3 & 2 & 2 & 3 & 2 & 3 & 3 & 3 \\
A7 & 4 & 4 & 4 & 2 & 2 & 2 & 2 & 3 & 3 \\
A8 & 2 & 2 & 2 & 2 & 4 & 3 & 3 & 2 & 2 \\
A9 & 2 & 2 & 3 & 2 & 2 & 2 & 2 & 4 & 3 \\
A10 & 3 & 3 & 2 & 2 & 2 & 4 & 2 & 2 & 3 \\
\hline
\end{tabular}

\section{Menghitung Skor Alternatif}

Langkah kedua adalah menghitung normalisasi matrik. Di sini, cara menhitung normalisasi pada WP adalah dengan menghitung skor $\left(\mathrm{S}_{\mathrm{i}}\right)$ pada masing-masing alternatif yang diperoleh dari hasil kuadrat masing-masing nilai dengan bobot masing-masing kriteria. 


$$
\begin{aligned}
& S_{i}= \prod^{n} n_{j=1} X_{i j}^{w j}, i=1,2, \ldots, \mathrm{m} \\
& S_{i}=\text { skor alterntaif } \\
& X_{i j}=\text { nilai pada matriks }(\mathrm{i}, \mathrm{j}) \\
& W_{j}=\text { bobot kriteria } \\
& \mathrm{S}_{i}=\left(3^{0,12}\right)\left(2^{0,04}\right)\left(2^{0,40}\right)\left(2^{0,08}\right)\left(2^{0,04}\right) \\
& \mathrm{S}_{i}=2,310075294
\end{aligned}
$$

Dengan rumus yang sama, kita terapkan ke semua alternative yang ada sehingga didapat hasil seperti table di bawah ini.

Tabel 12. Skor Alternatif

\begin{tabular}{cc}
\hline Nama Circle & Nilai Skor \\
\hline Makino & 2,310075294 \\
Cartenz & 2,65640248 \\
Dipping & 2,815895899 \\
Wendis & 2,407848088 \\
Kompi & 2,806022108 \\
\hline
\end{tabular}

\begin{tabular}{cc}
\hline Nama Circle & Nilai Skor \\
\hline Tempa & 2,419874747 \\
Kasep & 3,095549438 \\
Coin & 2,229920845 \\
Batik & 2,505211446 \\
Sate & 2,272911286 \\
\hline
\end{tabular}

\section{Menghitung Bobot Alternatif}

Dalam metode WP, untuk menghitung nilai bobot $(\mathrm{V})$ caranya adalah membagi skor alternatif dengan total skor alternatif. Dapat dilihat dengan rumus seperti dibawah ini.

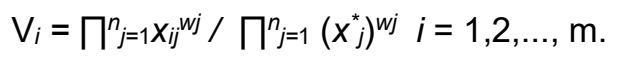

Contoh cara mengitung bobot $(\mathrm{V})$ alternatif

$$
\begin{aligned}
& \mathrm{V}_{i}=2,310075294 \\
& (2,310075294+2,65640248+2,815895899+2,407848088+2,806022108+ \\
& 2,419874747+3,095549438+2,229920845+2,505211446+2,272911286) \\
& V_{i}=0,090521215
\end{aligned}
$$

\section{Menghitung Masing-masing Bobot Alternatif}

Dengan rumus yang sama kita lakukan perhitungan terhadap semua laternatif seperti ditunjukan tabel dibawah ini :

Tabel 13. Nilai V Alternatif

\begin{tabular}{cc}
\hline Nama Circle & V \\
\hline Makino & 0,090521215 \\
Cartenz & 0,104092182 \\
Dipping & 0,110341995 \\
Wendis & 0,09435248 \\
Kompi & 0,109955087 \\
\hline
\end{tabular}

\begin{tabular}{cc}
\hline Nama Circle & V \\
\hline Tempa & 0,09482375 \\
Kasep & 0,12130033 \\
Coin & 0,087380331 \\
Batik & 0,098167702 \\
Sate & 0,089064928 \\
\hline
\end{tabular}

\section{Memilih Alternatif Terbaik}

Berdasarkan hasil perhitungan menggunakan metode WP, maka circle kasep adalah pemenang pada konvensi QIC seperti terlihat dalam tabel berikut.

Tabel 14. Perangkingan dengan WP

\begin{tabular}{ccc}
\hline Rangking & Nama Circle & V \\
\hline 1 & Kasep & 0,12130033 \\
2 & Dipping & 0,110341995 \\
3 & Kompi & 0,109955087 \\
4 & Cartenz & 0,104092182 \\
5 & Batik & 0,098167702 \\
\hline
\end{tabular}

\begin{tabular}{ccc}
\hline Rangking & Nama Circle & V \\
\hline 6 & Tempa & 0,09482375 \\
7 & Wendis & 0,09435248 \\
8 & Makino & 0,090521215 \\
9 & Sate & 0,089064928 \\
10 & Coin & 0,087380331 \\
\hline
\end{tabular}




\section{Perbandingan Metode Simpale Additive Weighting dan Weighted Product}

untuk melakukan perbandingan antara metode Simpale Additive Weighting dan Weighted Product dilakukan dengan cara melihat nilai akhir yang diperoleh alternatif dan rangking keputusan dengan tiga kondisi berbeda.

\section{Kondisi 1}

Melakukan penilaian terhadap 4 alternatif atau circle.

Tabel 15. Nilai Kondisi 1

\begin{tabular}{l|lllllllll}
\hline & $\mathbf{1}$ & $\mathbf{2}$ & $\mathbf{3}$ & $\mathbf{4}$ & $\mathbf{5}$ & $\mathbf{6}$ & $\mathbf{7}$ & $\mathbf{8}$ & $\mathbf{9}$ \\
\hline A1 & 3 & 2 & 2 & 2 & 2 & 4 & 3 & 2 & 2 \\
A2 & 3 & 3 & 3 & 2 & 3 & 3 & 2 & 3 & 2 \\
A3 & 2 & 3 & 4 & 2 & 2 & 2 & 2 & 3 & 3 \\
A4 & 2 & 4 & 2 & 3 & 4 & 4 & 2 & 4 & 3 \\
\hline
\end{tabular}

\section{Kondisi 2}

Melakukan penilaian terhadap 7 alternatif atau circle.

Tabel 16. Nilai Kondisi 2

\begin{tabular}{l|lllllllll}
\hline & $\mathbf{1}$ & $\mathbf{2}$ & $\mathbf{3}$ & $\mathbf{4}$ & $\mathbf{5}$ & $\mathbf{6}$ & $\mathbf{7}$ & $\mathbf{8}$ & $\mathbf{9}$ \\
\hline A1 & 3 & 2 & 2 & 2 & 2 & 4 & 3 & 2 & 2 \\
A2 & 3 & 3 & 3 & 2 & 3 & 3 & 2 & 3 & 2 \\
A3 & 2 & 3 & 4 & 2 & 2 & 2 & 2 & 3 & 3 \\
A4 & 2 & 4 & 2 & 3 & 4 & 4 & 2 & 4 & 3 \\
A5 & 4 & 2 & 3 & 3 & 2 & 2 & 3 & 2 & 2 \\
A6 & 3 & 3 & 2 & 2 & 3 & 2 & 3 & 3 & 3 \\
A7 & 4 & 4 & 4 & 2 & 2 & 2 & 2 & 3 & 3 \\
\hline
\end{tabular}

\section{Kondisi 3}

Melakukan penilaian terhadap 10 alternatif atau circle.

Tabel 17. Nilai Kondisi 3

\begin{tabular}{c|lllllllll}
\hline & $\mathbf{1}$ & $\mathbf{2}$ & $\mathbf{3}$ & $\mathbf{4}$ & $\mathbf{5}$ & $\mathbf{6}$ & $\mathbf{7}$ & $\mathbf{8}$ & $\mathbf{9}$ \\
\hline A1 & 3 & 2 & 2 & 2 & 2 & 4 & 3 & 2 & 2 \\
A2 & 3 & 3 & 3 & 2 & 3 & 3 & 2 & 3 & 2 \\
A3 & 2 & 3 & 4 & 2 & 2 & 2 & 2 & 3 & 3 \\
A4 & 2 & 4 & 2 & 3 & 4 & 4 & 2 & 4 & 3 \\
A5 & 4 & 2 & 3 & 3 & 2 & 2 & 3 & 2 & 2 \\
A6 & 3 & 3 & 2 & 2 & 3 & 2 & 3 & 3 & 3 \\
A7 & 4 & 4 & 4 & 2 & 2 & 2 & 2 & 3 & 3 \\
A8 & 2 & 2 & 2 & 2 & 4 & 3 & 3 & 2 & 2 \\
A9 & 2 & 2 & 3 & 2 & 2 & 2 & 2 & 4 & 3 \\
A10 & 3 & 3 & 2 & 2 & 2 & 4 & 2 & 2 & 3 \\
\hline
\end{tabular}

Pertama, dilakukan perhitungan dengan metode SAW dan didapat hasil akhir seperti berikut ini :

Tabel 18. Nilai Akhir dengan SAW

\begin{tabular}{cccc}
\hline \multirow{2}{*}{ Circle } & \multicolumn{3}{c}{ Perbaikan Bobot } \\
\cline { 2 - 4 } & $\mathbf{1}$ & $\mathbf{2}$ & $\mathbf{3}$ \\
\hline A1 & 0.69 & 0.66 & 0.66 \\
A2 & 0.76 & 0.73 & 0.73 \\
A3 & 0.82 & 0.80 & 0.80 \\
A4 & 0.71 & 0.69 & 0.69 \\
A5 & & 0.79 & 0.79 \\
A6 & & 0.69 & 0.69 \\
A7 & & 0.87 & 0.87 \\
A8 & & & 0.63 \\
A9 & & & 0.70 \\
A10 & & & 0.64 \\
\hline
\end{tabular}


Kedua, dilakukan perhitungan dengan metode WP dan dihasilkan data seperti berikut ini :

Tabel 19. Nilai Akhir dengan WP

\begin{tabular}{cccc}
\hline \multirow{2}{*}{ Circle } & \multicolumn{3}{c}{ Perbaikan Bobot } \\
\cline { 2 - 4 } & $\mathbf{1}$ & $\mathbf{2}$ & $\mathbf{3}$ \\
\hline A1 & 0.23 & 0.12 & 0.09 \\
A2 & 0.26 & 0.14 & 0.10 \\
A3 & 0.28 & 0.15 & 0.11 \\
A4 & 0.24 & 0.13 & 0.09 \\
A5 & & 0.15 & 0.11 \\
A6 & & 0.13 & 0.09 \\
A7 & & 0.17 & 0.12 \\
A8 & & & 0.09 \\
A9 & & & 0.10 \\
A10 & & & 0.09 \\
\hline
\end{tabular}

Dari kedua metode tersebut terlihat perbedaan yang sangat jelas dimana hasil alternatif pada metode SAW nilainya tetap sedangkan pada metode WP nilai akhir alternatif berubah saat dilakukan penambahan alternatif dan semakin kecil nilainya. Dengan demikian metode SAW lebih disarankan dalam SPK kali ini.

\section{Kesimpulan dan Saran}

\subsection{Kesimpulan}

Dari hasil penelitian yang telah dilakukan dihasilkan beberapak kesimpulan, diantaranya:

a. Metode Simple Additive Weighting dan Weighted Product dapat digunakan dalam SPK konvensi QIC.

b. Hasil akhir metode Simple Additive Weighting bernilai tetap sedangkan metode Weighted Product memiliki nilai akhir yang berubah sesuai banyaknya alternatif.

c. Metode Simple Additive Weighting lebih disarankan dalam SPK konvensi QIC.

\subsection{Saran}

Perbandingan yang digunakan hanya dilihat dari hasil akhir penilaian saja sehingga diperlukan beberapa variable lain dalam membandingkan kedua metode tersebut agar hasil yang didapat lebih akurat.

\section{Daftar Pustaka}

[1] Turban, E. 2005. Decision Support System and Inteligent System, seventh edition, diterjemahkan oleh Tim Penerjemah ANDI, Sistem Pendukung Keputusan dan Sistem Cerdas, edisi 7, Jilid I dan II, Yogyakarta: ANDI.

[2] Adriyendi. 2015. Multi-Attribute Decision Making Using Simple Additive Weighting and Weighted Product in Food Choice, International Journal Information Engineering and Electronic Business 8-14, MECS.

[3] Satzinger J., Jackson R., Burd S. 2007. System Analysis and Design in a Changing World, fourth edition, Boston: Course Techonogy. 